\title{
Effects of plants development and pollutant loading on performance of vertical subsurface flow constructed wetlands
}

\author{
${ }^{1}$ B .Cheng; ${ }^{2}$ C. W. Hu; ${ }^{3} *$ Y. J. Zhao \\ ${ }^{1}$ Department of Biology and Chemistry, Huainan Normal University, 238 The west Tongshan Road, Huainan \\ 232001, China \\ ${ }^{2}$ School of Life Science, Linyi Normal University, 18 Tongda Road, Linyi 276005, China \\ ${ }^{3}$ Environmental Science and Engineering Department, Fudan University, Shanghai 200433, China
}

Received 19 March 2010; revised 26 July 2010; accepted 15 November 2010; available online 1 December 2010

\begin{abstract}
The influent concentration has a great effect on nutrients removal efficiency in vertical subsurface flow constructed wetland systems, but treatment performance response to different $\mathrm{C}$ : $\mathrm{N}$ : P ratios in the influent are unclear at present. At the first growing seasons, the effects of the plants present or not, season, the different C: N: P ratio in influent condition and their interaction on treatment performances were studied in the planted or the unplanted wetlands in greenhouse condition. Each set of units was operated at hydraulic loading rates of $40 \mathrm{~L} / \mathrm{d}$. Low, medium and high-strength (100, 200, $400 \mathrm{mg} / \mathrm{L}$ of chemical oxygen demand or 20, 40, $80 \mathrm{mg} / \mathrm{L}$ total nitrogen) synthetic sewage were applied as influent. According to the first growing season results, the average removal efficiencies for the unplanted and the planted wetlands were as follows: chemical oxygen demand (44-58 \% and 55-61 \% respectively), total nitrogen (26$49 \%$ and $31-54 \%$ ) and total phosphorus (36-64\% and 70-83\%). The both wetlands system was operated as an efficient treatment system of highest average removal rates of both chemical oxygen demand and total phosphorus when medium-strength synthetic sewage were applied. When high strength synthetic sewage was applied, the planted wetlands usually had a higher nutrients removal rates than the unplanted over the study period. The plants grew well under any high loading treatment over the study period. Anyhow, it also proved that the wetland systems have a good capacity to treat different strength wastewater in greenhouse condition.
\end{abstract}

Key words: Acorus calamus; C: N: P ratio; Nutrients removal rates; Seasonal variation; Vertical flowconstructed wetlands

\section{INTRODUCTION}

Vertical subsurface flow constructed wetlands (VSCWs), which are of low cost, easily operated and maintained, can be potentially applied in developing countries with serious water pollution problems (Seo et al., 2005; Baptista et al., 2008; Li et al., 2008). They are emerging as a very useful technology for the treatment of a variety of wastewaters (Baptista et al., 2003; Juang and Chen, 2007; Okafor and Opuene, 2007; Tsihrintzis et al., 2007; Harikumar et al, 2009; Igbinosa and Okoh, 2009). An important part of the treatment in constructed wetlands is attributable to the presence and activity of plants and microorganisms (Nwuche and Ugoji, 2008 and 2010). The plants growing in CWs are the most obvious visual characteristic of the

*Corresponding Author Email: zyjun2007@126.com Tel.: +8621 65642948; Fax: +862165642948 systems. Many studies have demonstrated that the plants contribute to water treatment through both direct and indirect mechanisms (Edwards et al., 2006; Alam, et al., 2007; Mahvi, 2008; Nameni et al., 2008; Nouri et al., 2008). According to the related research, most marsh plants can work best in VSCWs wastewater treatment systems (Koottatep et al., 2001; Stottmeister et al., 2003; Calheiros et al., 2009). This is because helophytes possess specific characteristics of growth physiology that guarantee their survival even under extreme rhizosphere conditions. These systems can effectively remove both organic material and total suspended solids from wastewater, although nitrogen and phosphorus removal is known to be somewhat problematic (Cooper, 1999; Brix et al., 2001; Lu and Huang, 2010). 
). In pollution monitoring activities for water bodies, COD, TN and TP are an important water quality indicators and descriptors of effluent content (Coveney et al., 2002; Li et al., 2008). Most wastewater treatment programs are based on these indices as the main, often the specific, calibration variables for waste loading (Tang et al., 2009). The actual treatment performance for the three parameters will mainly depend on a variety of factors, including the VCWs system itself and the polluted water and the specific way it is applied to the bed (Prochaska et al., 2007). The system related factors include mainly the substrate size, the depth of bed, the used macrophyte species, the maturity of bed, and the effect of climate (Merlin et al., 2002). The application-related factors include mainly the hydraulic loading rate and the residence time, the influent concentration, the proportion of various pollutants (Enriquez et al., 1993; Prochaska and Zouboulis, 2009). Climate and other local conditions influence wastewater characteristics, plant growth and evaporation as well as the removal processes in the constructed wetland, particularly the microbial processes which are expected to be stimulated by the high temperatures (Abdel-Ghani and Elchaghaby, 2007; Abdel-Ghani et al., 2009; Kantawanichkul et al., 2009; ). In particular, the treatment performance of vertical subsurface flow systems in response to seasonal variation, plant presence, and influent $\mathrm{C}$ : $\mathrm{N}$ : $\mathrm{P}$ ratio is still rather incomplete. If wastewater is to be treated as efficiently as possible, a full understanding about the relationship between the treatment performance of vertical subsurface flow systems and the change of wastewater components in the planted and unplanted wetlands at different season is necessary. The key to efficient biological wastewater treatment relies on knowledge of the plant development involved and how they respond to different pollutant loading conditions. Maybe, the different strength wastewater in the influent could cause different efficiencies of nutrients removal rates. In order to address the problem, experiments were conducted on treating simulated wastewater with different $\mathrm{C}: \mathrm{N}$ : $\mathrm{P}$ ratios in VCWs system.In this study, COD, TN concentrations, and their weighted ratios in synthetic domestic wastewater were adjusted, while maintaining constant TP concentrations. The purpose of this study were to investigate the ability of vertical flow constructed wetland systems to treat different strength (COD or
TN ) wastewater, and to evaluate the performance of systems planted with Acorus calamus (hereafter referred to as Acorus ) and the unplanted systems. In addition, the effect of season on treatment performances in the planted and the unplanted was studied in order to determine how treatment performance responded to seasonal variation, and thus to explain and predict the performance of an operating wetlands system at different periods. The experiments were set up in the greenhouse of Nanjing University, China ( $\left.32^{\circ} 10^{\prime} 370 \mathrm{~N}, 118^{\circ} 41^{\prime} 570 \mathrm{E}\right)$. The operation and monitoring of the wetlands were conducted between May, 2008, and January, 2009.

\section{MATERIAL AND METHODS}

Description of the treatment wetland

The pilot-scale wetlands were two types of vertical subsurface-flow constructed wetlands (VSCWs), one planted with the rhizomatous herb Acorus, and the other unplanted. The wetland frame, $1.00 \mathrm{~m}$ (length) $\times 0.60 \mathrm{~m}$ (width) $\times 0.80 \mathrm{~m}$ (height) were made of reinforced cement, and were filled with gravel (nominal mean diameter of $1.20 \mathrm{~cm}$ ) up to a depth of $0.20 \mathrm{~m}$ in the lower layer and with slag (nominal mean diameter of $1.50 \mathrm{~cm}$ ) up to a depth of $0.25 \mathrm{~m}$ in the upper layer (Fig. 1). Two types of experimental wetlands were run in parallel under identical conditions for 270 days.

The temperature in both VSCWs ranged between $6.4^{\circ} \mathrm{C}$ and $40.8{ }^{\circ} \mathrm{C}$, and averaged $17.9^{\circ} \mathrm{C}$. At April 5, 2008 a half of the wetlands were planted with Acorus (16.37 $\pm 1.59 \mathrm{~cm}$ tall), using 8-10 stems per wetland. After planting, they were kept flooded for one month with tap water, and then the influent water was administered to the wetlands. When operational the hydraulic loading rate of simulated sewage was 40L/ $\mathrm{d}$ applied as a single batch through a round PVC pipe of $5 \mathrm{~cm}$ internal diameter. The pipe, perforated with holes of $1.5 \mathrm{~mm}$, was placed on one side of the wetland surface. The wetland substrates held $60 \mathrm{~L}$ of water; batch volumes of $40 \mathrm{~L}$ were applied fortnightly to each wetland with a constant flow rate of $15 \mathrm{~L} / \mathrm{min}$ achieving an overall hydraulic retention time (HRT) of 1.5 days. The batch volumes of $200 \mathrm{~L}$ were applied weekly to each wetland by gravity action for 5 days each time, and the other two days is a dormant period. All treatments, including the control, were triplicated and a total of 36 wetlands were used for the study.For health and safety 
reasons, as well as for comparison of the parallel experiments, the wetlands were fed with synthetic wastewater, simulating low, medium and high (COD or TN level) and medium strength (TP) domestic sewage. Design methods of the variation of $\mathrm{C}, \mathrm{N}$ and $\mathrm{P}$ ration was fixed nitrogen, phosphorus levels (medium strength) and various proportions of carbon dosing quantity. The synthetic sewage was a modification of OECD standard sewage (OECD, 1996) and it was prepared prior to each (batch) feeding by mixing (in tap water) the following different components: $100,200,400 \mathrm{~g} / \mathrm{m}^{3}$ glucose, $15 \mathrm{~g} / \mathrm{m}^{3}$ $\mathrm{NaH}_{2} \mathrm{PO}_{4}, 1.5 \mathrm{~g} / \mathrm{m}^{3} \mathrm{KH}_{2} \mathrm{PO}_{4}, 4 \mathrm{~g} / \mathrm{m}^{3} \mathrm{CaCl}_{2}, 2 \mathrm{~g} / \mathrm{m}^{3}$ $\mathrm{MgSO}_{4}$. The other treating method was fixed carbon, phosphorus levels (medium strength) and various proportions of nitrogen dosing quantity. The following different components: $200 \mathrm{~g} / \mathrm{m}^{3}$ glucose, 40, 80, $160 \mathrm{~g} / \mathrm{m}^{3}$ carbamide, $15 \mathrm{~g} / \mathrm{m}^{3} \mathrm{NaH}_{2} \mathrm{PO}_{4}, 1.5 \mathrm{~g} /$ $\mathrm{m}^{3} \mathrm{KH}_{2} \mathrm{PO}_{4}, 4 \mathrm{~g} / \mathrm{m}^{3} \mathrm{CaCl}_{2}, 2 \mathrm{~g} / \mathrm{m}^{3} \mathrm{MgSO}_{4}$. The experimental influent conditions applied to the unplanted are same as the planted wetlands (Table 1and 2).

\section{Measurement of water quality parameters}

From May, 2008 to January, 2009, in operation stage, influent and effluent water of the pilot-scale VSCWs were sampled by opaque plastic bottle (100 $\mathrm{ml}$ ) from inlet and outlet (Fig. 1) approximately every week under normal conditions to monitor water quality. Mean values of three sampling sites in each wetland were used to eliminate the space difference. Water samples were analyzed for COD, TN and TP. COD was determined by the titrimetric method. Water TN were measured using liquor TOC a! (Munich, Germany; detection limit: $0.00001 \mathrm{mg} / \mathrm{L}$ ), while TP were performed using a segmented flow analysis (Automated Chemistry Analyzer, Brighton, U.K; detection limit: $0.001 \mathrm{mg} / \mathrm{L}$ ). In this study, all the parameters mentioned above were determined according to the method as described in the standard method for Examination of Water and Wastewater.

\section{Statistical analyses}

Treatment efficiencies were calculated as the percent removal ( $\mathrm{R}$ ) for each parameter, calculated by $R=\left(1 C_{e} / C_{i}\right) \times 100$, where $C_{i}$ and $C_{e}$ were the influent and effluent concentrations in $\mathrm{mg} / \mathrm{L}$, respectively. Mean effluent values for every batch sampling over each month were used to calculate removal rates for each parameter.All statistical analyses were performed using SPSS software (SPSS, 2003), One-way ANOVA was used to test the differences in related parameters of the two wetlands under different influent conditions. Two-way ANOVA was used to test differences in the effects of

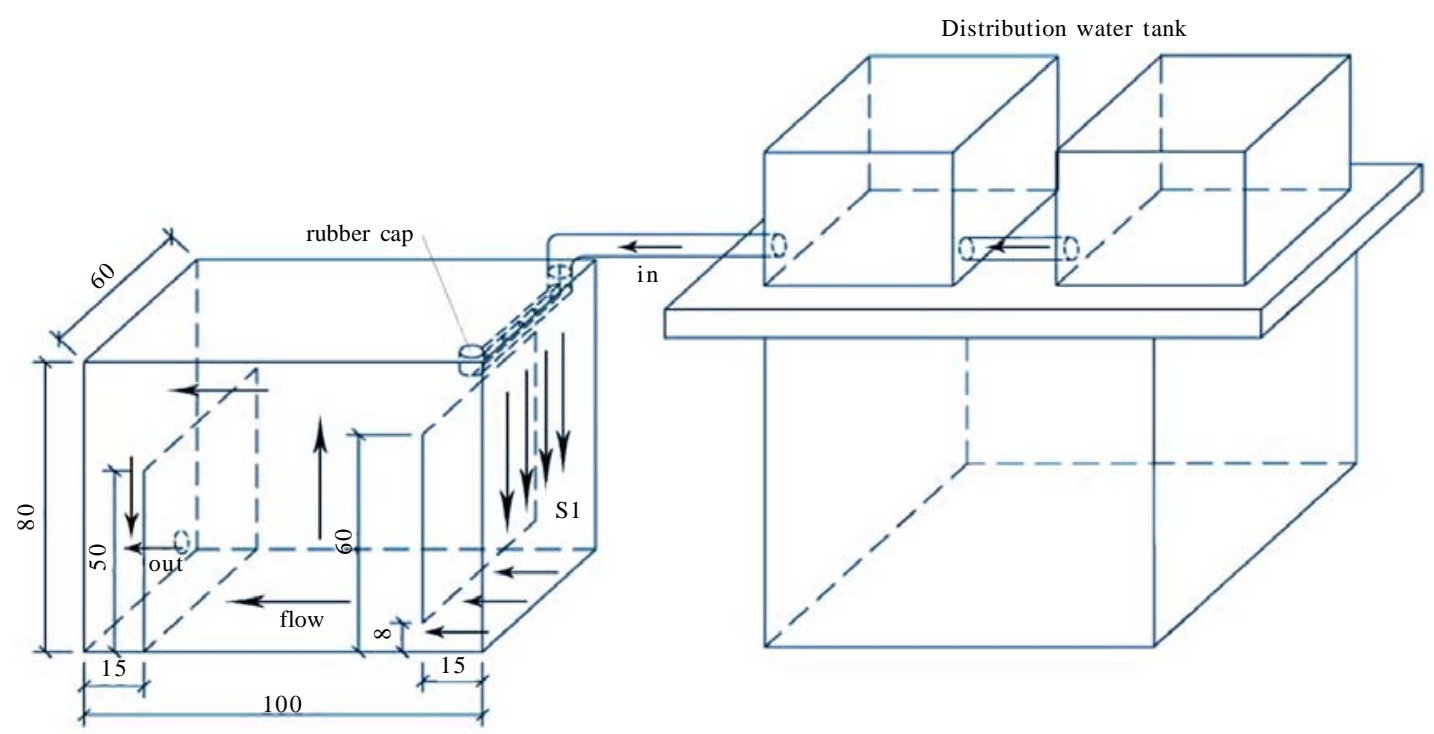

Fig. 1: Diagram of the pilot-scale wetlands used in this study 
carbon or nitrogen treatments, plant patterns, season and their cross-reaction on treatment performance. Duncan's multiple range test was used to further assess differences among treatment combinations that were significant in ANOVA.

\section{RESULTS AND DISCUSSION}

Water quality and removal performance

Values of COD, TN and TP differed significantly between the two VSCWs for $\mathrm{C}$ or $\mathrm{N}$ addition treatments. For $\mathrm{C}$ treatments, only differences in removal efficiencies of TP for the same treatments was significant $(P<0.05)$ between the unplanted and the planted wetlands (Table 1). Other parameters in the effluent were not significantly different between the two VSCWs for the same $C$ treatments $(P>0.05)$ (Table 1). Multiple comparisons detected significantly higher TP removal rates in all $\mathrm{C}$ treatments in the planted wetlands than those in the planted wetlands over the study period.For $\mathrm{N}$ treatments, table 2 shows there were no significant differences in COD removal rates among $\mathrm{N}$ treatments in the two wetlands $(P>0.05)$. Moreover, the CN1P treatment had a lower $\mathrm{TN}$ removal rate than the $\mathrm{CN} 2 \mathrm{P}$ and $\mathrm{CN} 4 \mathrm{P}$ treatments in the two planted, and a significant difference $(P<0.05)$ occurred between the CN1P and the CN4P treatments during the wetlands operational period. No significant differences were observed in removal rates of $\mathrm{TP}$ among different $\mathrm{N}$ treatments in the planted wetlands $(P>0.05)$, the CN2P treatments showed higher TP removal rates than CN1P and CN4P treatments. In the unplanted wetlands, a significant treatment effect was observed in the removal rate of TP among different $\mathrm{N}$ addition treatments $(P<0.05)$. Differences in removal rates of TP were found between the unplanted and planted wetlands in all the same $\mathrm{N}$ treatments $(P<0.05)$. [Table 1 , Table 2 inserted here]The organic pollutant load, measured as COD, of the wastewater treated in the present study, is relatively high. The two wetlands removed efficiently the contained COD during the whole experimental period. In the two VSCWs, the COD removal rates varied between 55 and $61 \%$ for the planted system and 44 and $58 \%$ for unplanted. The concentration-based removal efficiency of 44-61\% for COD in this study was higher than $44-47 \%$ which was reported by Korkusuz et al. (2005) for slag wetland systems. The both wetlands system was operated as an efficient treatment system of highest average removal rates of COD when mediumstrength (200 mg/L of COD and $40 \mathrm{mg} / \mathrm{L} \mathrm{TN}$ ) synthetic sewage were applied. Thus, appropriate control of the carbon or nitrogen source concentrations could achieve optimal COD removal. In this study, plants seemed to have little influence on COD removal rates, the planted wetlands did not show a higher removal than unplanted beds under any $\mathrm{C}$ : $\mathrm{N}$ : P ratio influent condition. Other studies comparing planted and unplanted beds have also shown no or only little difference in removals of COD between the beds. At high COD loading ( $\mathrm{C} / \mathrm{N}=10: 1)$, the poor removal of $\mathrm{TN}$ in the two wetlands was probably caused by the high COD concentrations that may inhibit microbiological processes. Also, aerobic conditions that support the nitrification are not suitable for denitrification (Prochaska and Zouboulis, 2009). Likewise, at low TN loading $(\mathrm{C} / \mathrm{N}=10: 1)$, the $\mathrm{TN}$ removal rates (inflow TN concentration $20 \mathrm{Mg} / \mathrm{L}$ ) was unsatisfactory (30\% in the panted and $25 \%$ in the unplanted). Phosphorus removal by constructed wetlands is a key strategy in diffuse pollution control (Tang et al., 2006). During the whole study period, the two VSCWs were more effective for TP removal. The average results in both wetlands (Table 1 and Table 2) were higher in comparison to the typical removal of 20-30 \% reported in many VSCWs (Luederitz et al., 2001; Brix and Arias, 2005). These results were more similar to the removal rate of $45 \%$ found by Korkusuz et.al (2005) who used slag as substrate material a mixture of river sand and dolomitic limestone. This results confirm the good capacity of the selected substrate for phosphorous removal (Zurita et al., 2006), and they could be probably improved by reducing the substrate size, and then promoting phosphorous removal by chemical adsorption (Prochaska et al., 2007). Akratos and Tsihrintzis (2007) found that planted wetlands had 40 $\%$ higher removals of TP than unplanted wetlands. Thus, plants can contribute to $\mathrm{P}$ removal, but the quantitative significance of that removal is variable and depends on influent quality, plant species, season, and other factors (Konnerup et al., 2009). The amount of $\mathrm{P}$ removed by plant uptake was not quantified, but it was assumed that a large part of it was removed by the bed substrate. In this study the performance, in terms of contaminant removal with special focus on influent $\mathrm{C}$ : $\mathrm{N}$ : $\mathrm{P}$ ratio, and plant development, of two series of VSCWs planted with 
Acorus and the unplanted was evaluated. Acorus was the plant that established most successfully in the VSCWs, since it showed a good resistance to the alterations in the loadings applied to the systems.

\section{Time course of removal of pollutant}

Nutrient removal rates fluctuated in each unit during the wetlands operational period. With the exception of winter (November-January), the planted wetlands for the two types of addition treatments showed a similarly higher trend in COD removal than the unplanted wetlands (Fig. 2).

In respect to $\mathrm{C}$ treatments, the $\mathrm{C} 2 \mathrm{NP}$ treatments showed higher COD removal rates than C1NP and C4NP treatments from August to November in the planted wetlands, whereas in the unplanted wetlands, the C2NP treatments usually had higher COD removal rates from November to January (Fig. 2a). Thus COD removal rates were significantly affected by season and the combined effect of plant presence and season (Table 3) $(P<0.01)$. For N treatments, the CN2P treatments usually also had higher COD removal rates with different TN level treatments (Fig. 2b), and season had a significant effect on COD removal (Table 4) $(P<0.01)$. According to the data presented in Fig. 2 demonstrated higher COD removal rates from May to July (43-94 \%), possibly due to higher summer temperatures, which favor the decomposition of organic compounds as suggested by Kayser and Kunst (2005).The results of analysis indicated that the influent $\mathrm{C}: \mathrm{N}$ : Pratio has no significant role in differential removal of organic matter. TN removal rates fluctuated in both wetlands under all influent conditions, especially for planted wetlands from September to November under all $\mathrm{C}$ : N: P ratio in the influent. For C treatments, higher TN removal effects appeared in July and August in the planted wetlands. However, in October, the elimination of TN remained relatively the lowest in the planted system. The C1NP treatments also usually had higher $\mathrm{TN}$ removal rates among different $\mathrm{C}$ treatments (Fig. 3a), while under $\mathrm{N}$ treatments the CN2P treatments had higher TN removal rates especially in autumn (Fig. 3b). In the unplanted wetlands, the C2NP or CN2P treatments usually had higher TN removal rates among different COD or TN level treatments from August to November. In spite of the TN

Table 1: Mean concentrations \pm SD in the influent and pollutant removal efficiencies for chemical oxygen demand (COD), total nitrogen (TN) and total phosphorus (TP) in the effluent waters of the two VSCWs under C treatments. Values with different superscript letters in the same column indicate a significant difference at $\mathrm{P}<0.05$ according to Duncan's multiple range test

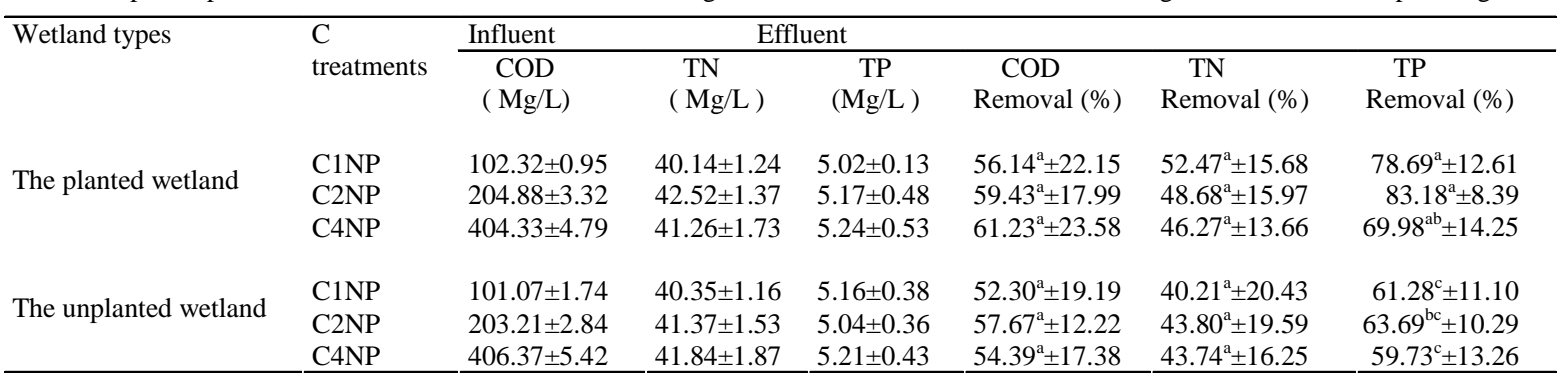

Table 2: Mean concentrations \pm SD in the influent and pollutant removal efficiencies for chemical oxygen demand (COD), total nitrogen (TN) and total phosphorus (TP) in the effluent waters of the two VSCWs under $\mathrm{N}$ treatments. Values with different superscript letters in the same column indicate a significant difference at $P<0.05$ according to Duncan's multiple range test

\begin{tabular}{|c|c|c|c|c|c|c|c|}
\hline \multirow[t]{2}{*}{ Wetland types } & \multirow{2}{*}{$\begin{array}{l}\mathrm{N} \\
\text { treatments }\end{array}$} & Influent & \multicolumn{2}{|c|}{ Effluent } & & & \\
\hline & & $\begin{array}{c}\text { COD } \\
(\mathrm{Mg} / \mathrm{L})\end{array}$ & $\begin{array}{l}\text { TN } \\
(\mathrm{Mg} / \mathrm{L})\end{array}$ & $\begin{array}{c}\text { TP } \\
(\mathrm{Mg} / \mathrm{L})\end{array}$ & $\begin{array}{c}\text { COD } \\
\text { Removal (\%) }\end{array}$ & $\begin{array}{c}\text { TN } \\
\text { Removal (\%) }\end{array}$ & $\begin{array}{c}\text { TP } \\
\text { Removal (\%) }\end{array}$ \\
\hline \multirow{3}{*}{ The planted wetland } & CN1P & $203.56 \pm 2.62$ & $22.06 \pm 1.44$ & $5.13 \pm 0.21$ & $56.52^{\mathrm{a}} \pm 21.14$ & $30.65^{\mathrm{bc}} \pm 11.19$ & $77.08^{\mathrm{a}} \pm 9.06$ \\
\hline & CN2P & $204.57 \pm 3.86$ & $40.58 \pm 1.71$ & $5.05 \pm 0.18$ & $59.43^{\mathrm{a}} \pm 17.99$ & $49.68^{\mathrm{ab}} \pm 15.97$ & $83.18^{\mathrm{a}} \pm 8.39$ \\
\hline & CN4P & $202.64 \pm 3.27$ & $81.06 \pm 2.53$ & $5.02 \pm 0.11$ & $55.27^{\mathrm{a}} \pm 20.88$ & $54.08^{\mathrm{a}} \pm 9.36$ & $69.63^{\mathrm{a}} \pm 14.21$ \\
\hline \multirow{3}{*}{ The unplanted wetland } & CN1P & $202.17 \pm 3.05$ & $20.84 \pm 0.57$ & $5.08 \pm 0.14$ & $46.11^{\mathrm{a}} \pm 15.71$ & $25.86^{\mathrm{c}} \pm 13.38$ & $35.52^{\mathrm{d}} \pm 13.35$ \\
\hline & CN2P & $200.21 \pm 4.05$ & $41.42 \pm 1.12$ & $5.27 \pm 0.31$ & $52.76^{\mathrm{a}} \pm 12.85$ & $44.80^{\mathrm{a}} \pm 19.59$ & $57.78^{\mathrm{b}} \pm 8.15$ \\
\hline & CN4P & $203.38 \pm 4.26$ & $82.05 \pm 2.42$ & $5.17 \pm 0.26$ & $44.22^{\mathrm{a}} \pm 28.47$ & $47.42^{\mathrm{a}} \pm 17.84$ & $49.89^{c} \pm 12.51$ \\
\hline
\end{tabular}




\section{B. Cheng et al.}

Table 3: P-values of factors and the combined effects of factors for each parameter under carbon variation treatment based on the analysis of variance. Plant pattern: planted or unplanted; season: from May to January; ${ }^{*} P<0.05, * * P<0.01$

\begin{tabular}{llll}
\hline Factors & \multicolumn{1}{c}{ COD } & TN & TP \\
& removal (\%) & removal (\%) & removal (\%) \\
\hline Plant pattern & 0.082 & 0.073 & $0.001^{* *}$ \\
Carbon variation & 0.526 & 0.082 & 0.437 \\
Season & $<0.0001^{* *}$ & $0.001^{* *}$ & $<0.0001^{* *}$ \\
Plant pattern $\times$ carbon variation & 0.254 & 0.076 & 0.372 \\
Plant pattern $\times$ season & $0.001^{* *}$ & $0.041^{*}$ & $0.035^{*}$ \\
Carbon variation $\times$ season & 0.476 & 0.684 & 0.592 \\
\hline
\end{tabular}
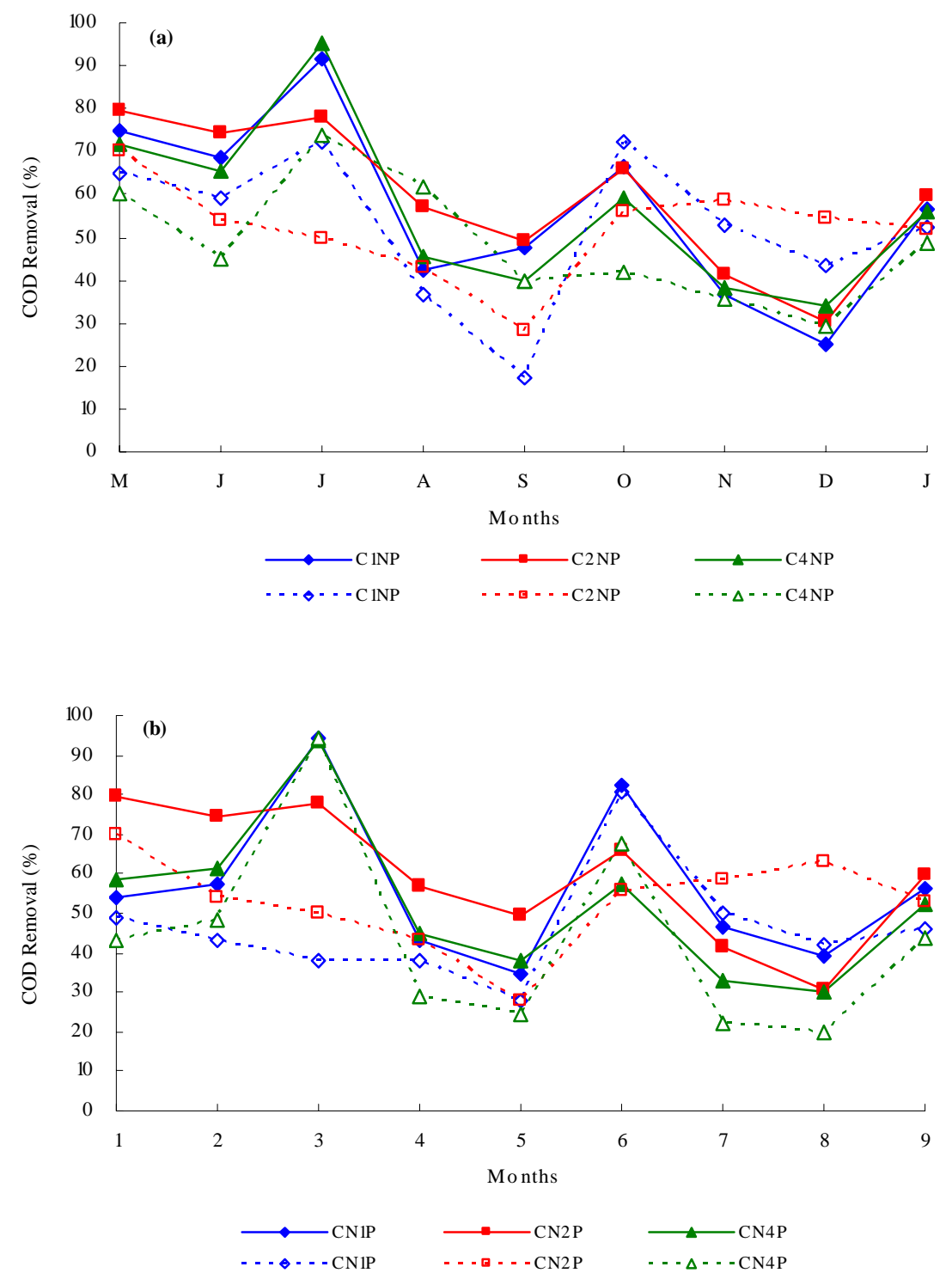

Fig. 2: Temporal course of removal rates of COD in the planted (solid line) and unplanted (dotted line) wetlands during the wetlands operational period. a: C treatment; b: N treatment 
Table 4: The P-values of factors and the combined effects of factors for each parameter under nitrogen variation treatment based on the analysis of variance. Plant pattern: planted or unplanted; season: from May to January; asterisks: $* P<0.05, * * P<0.01$

\begin{tabular}{|c|c|c|c|}
\hline Factor & $\begin{array}{c}\text { COD } \\
\text { removal (\%) }\end{array}$ & $\begin{array}{c}\mathrm{TN} \\
\text { removal (\%) }\end{array}$ & $\begin{array}{c}\mathrm{TP} \\
\text { removal (\%) }\end{array}$ \\
\hline Plant pattern & 0.096 & 0.115 & $<0.0001^{* *}$ \\
\hline Nitrogen variation & 0.315 & $0.001^{* *}$ & $<0.0001 * *$ \\
\hline Season & $<0.0001^{* *}$ & $<0.0001 * *$ & $0.001 * *$ \\
\hline Plant pattern $\times$ nitrogen variation & 0.287 & 0.152 & 0.253 \\
\hline Plant pattern $\times$ season & 0.079 & 0.423 & 0.375 \\
\hline Nitrogen variation $\times$ season & 0.465 & 0.521 & 0.716 \\
\hline
\end{tabular}
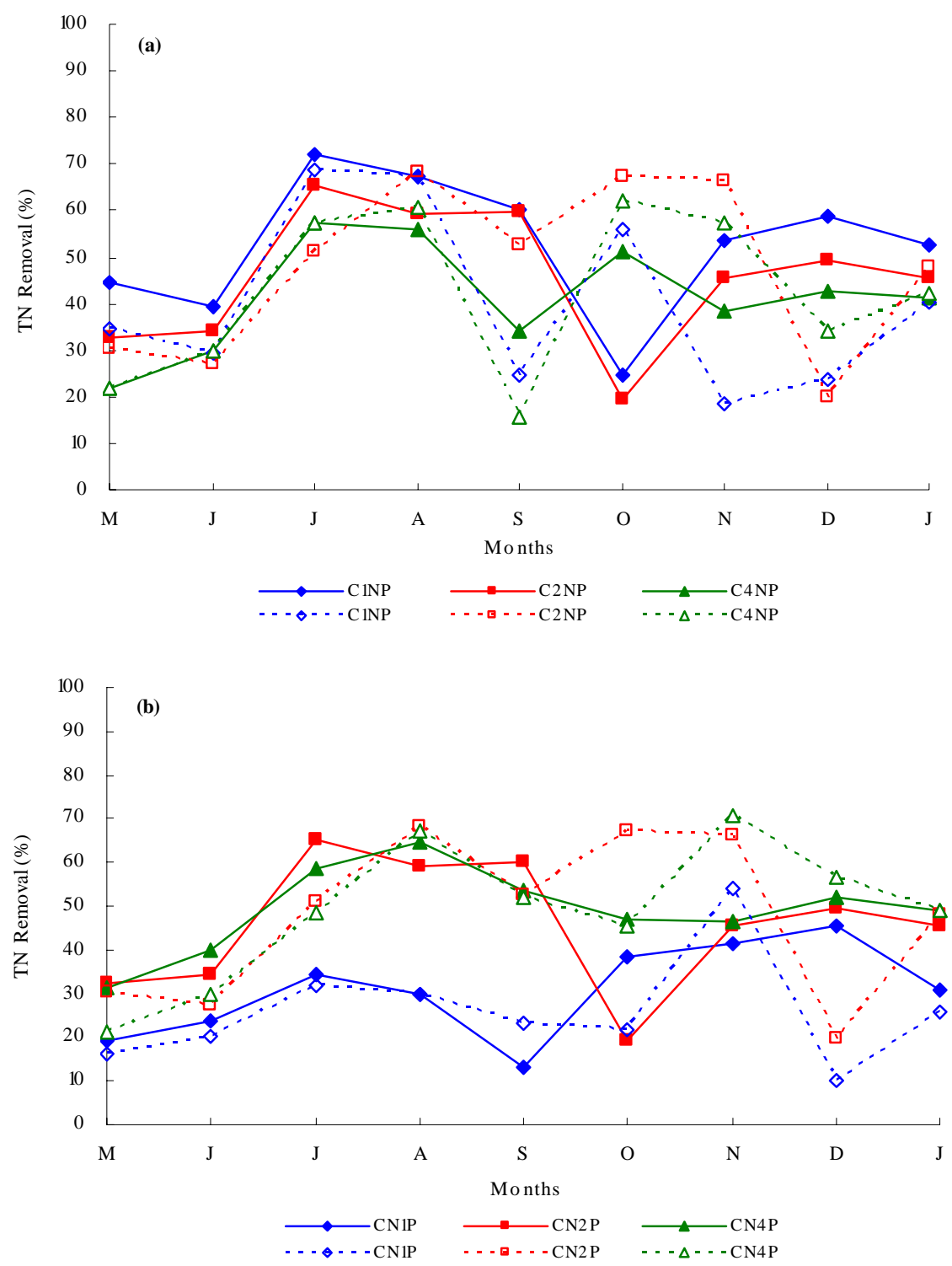

Fig. 3: Temporal course of removal rates of total nitrogen in the planted (solid line) and unplanted (dotted line) wetlands during the wetlands operational period. a: C treatment; b: $\mathrm{N}$ treatment 

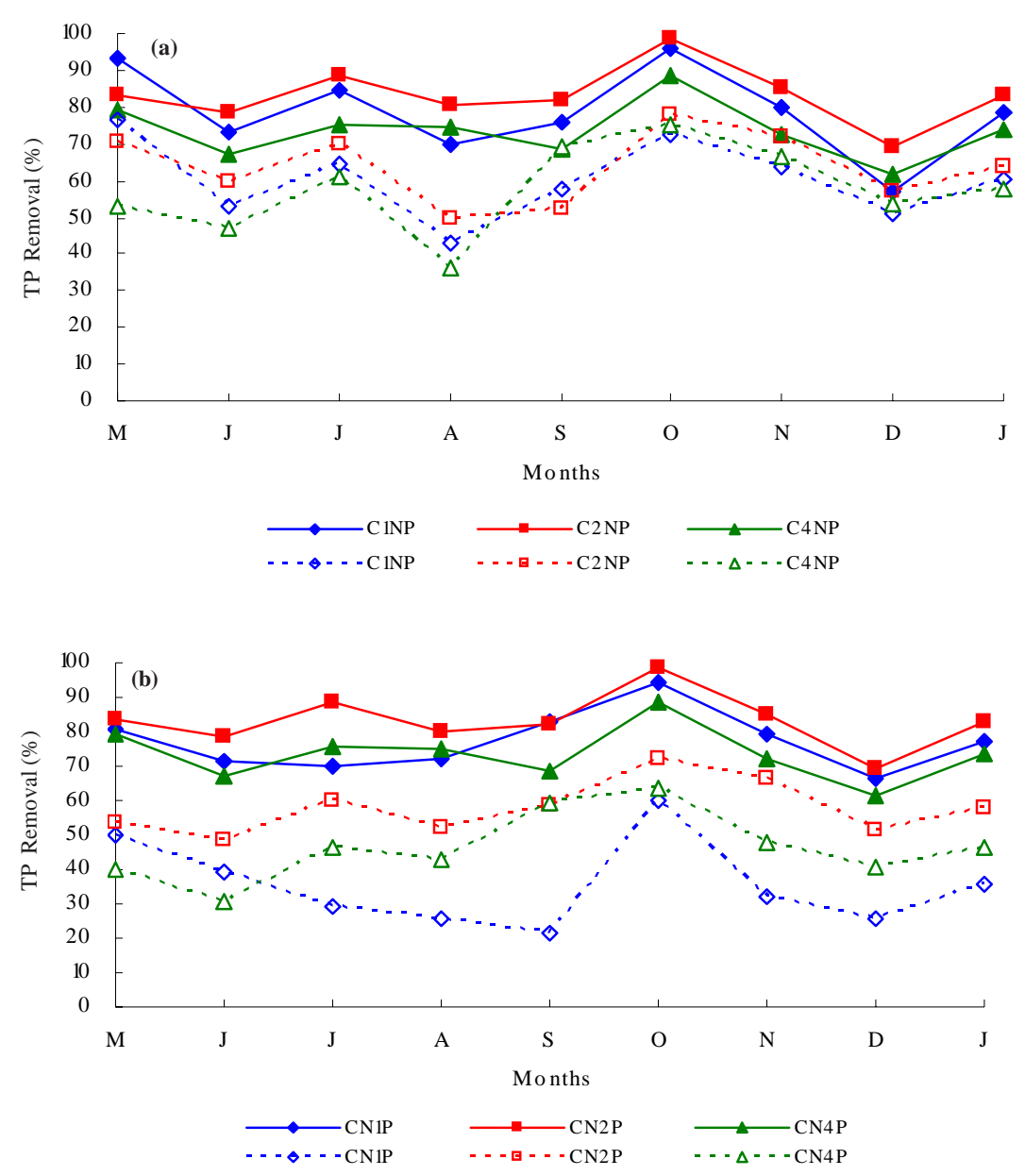

Fig. 4: Temporal course of removal rates of total phosphorus in the planted (solid line) and unplanted (dotted line) wetlands during the wetlands operational period. a: $\mathrm{C}$ treatment; b: $\mathrm{N}$ treatment

removal-process fluctuations of the two wetlands over the study period, it was found that the planted wetlands were more effective than the unplanted especially in summer, this possibly attributable higher plant uptake. Furthermore, the TN removal effect index was significantly affected by season and plant $\times$ season interaction under $\mathrm{C}$ treatments and by nitrogen variation and season in the nitrogen addition treatments $(P<0.01)$ (Tables 3 and 4$)$. The removal rate of TP was higher in the planted wetlands than in the unplanted with both $\mathrm{C}$ and $\mathrm{N}$ treatments (Fig. 4). Higher TP removal effects occurred in autumn in both wetlands. However, the removal rates of TP were relatively lower in winter (November -January). All the two VSCWs showed efficient TP removal during the start-up period of this study (Fig. 4). This implies that gravel/slag adsorption determined initial efficient phosphorus removal (Lin et al., 2002). The ability of adsorption may decrease with time especially from October to January when sorption sites on the gravel/ soil become saturated. Moreover, the C2NP or CN2P treatments usually had higher TP removal rates among different $\mathrm{C}$ or $\mathrm{N}$ treatments. Table 3 shows that season, plant pattern and plant $\times$ season interaction had significant effect on removal rates of TP under $C$ treatments $(P<0.05)$. On the other hand, the P-values for the TP parameter, presented in Table 4, showed that nitrogen variation, season and plant pattern had a significant effect on removal rates of TP under $\mathrm{N}$ treatments $(P<0.01)$. 


\section{CONCLUSION}

Two series of vertical subsurface flow constructed wetlands, operating under different $\mathrm{C}$ : $\mathrm{N}$ : $\mathrm{P}$ ratio in the influent, were evaluated in terms of performance, establishment and adequacy to be applied to simulated wastewater treatment. The main conclusions of this investigation are summarized as follows. VSCWs can be subjected to higher COD and TN loadings than those suggested in the literature, allowing for health and safety reasons of plants and microorganism, which is advantageous for domestic wastewater treatment applications.

As expected, the pollutant removal rate in the VSCWs depended on the plants present, plant development, and C: N: P ratio in the influent. With exception of COD, the removal of nitrogen and phosphorus were higher in the planted wetlands. Nutrient removal rates fluctuated in each wetland during the wetlands operational period. The growth season of plants had a significant effect on COD, TN and TP removal. Therefore, plant development appeared to have a significant benefit in the treatment process in the vertical subsurface flow constructed wetlands. The both wetlands system was operated as an efficient treatment system of highest average removal rates of both COD and TP when mediumstrength (200 mg/L of COD and $40 \mathrm{mg} / \mathrm{L} \mathrm{TN}$ ) synthetic sewage were applied. Moreover, with exception of lowstrength of TN (20 mg/L TN) in the influent, both wetlands exhibited good capabilities of total nitrogen removal. Therefore, appropriate control of pollutant loading in the influent could achieve optimal nutrient removal.

\section{ACKNOWLEDGEMENTS}

The authors would like to thank the colleagues and students from Nanjing University for maintaining the treatment wetland systems during the study period. This study is financially supported by the National Water Special Project of China (No. 2008ZX07010-001-004 and 2008ZX07526-002-003).

\section{REFERENCES}

Abdel-Ghani, N. T.; Elchaghaby, G. A., (2007). Influence of operating conditions on the removal of $\mathrm{Cu}, \mathrm{Zn}, \mathrm{Cd}$ and $\mathrm{Pb}$ ions from wastewater by adsorption. Int. J. Environ. Sci. Tech. 4 (4), 451-456 (6 pages).

Abdel-Ghani, N. T.; Hegazy, A. K.; El-Chaghaby, G. A., (2009). Typha domingensis leaf powder for decontamination of aluminium, iron, zinc and lead: Biosorption kinetics and equilibrium modeling. . Int. J. Environ. Sci. Tech., 6 (2), 243-248 (6 pages).

Akratos, C. S.; Tsihrintzis, V. A., (2007). Effect of temperature, HRT, vegetation and porous media on removal efficiency of pilot-scale horizontal subsurface flow constructed wetlands. Ecol. Eng., 29 (2), 173-191 (19 pages).

Alam, Md. J. B.; Islam, M. R.; Muyen, Z.; Mamun, M.; Islam, S., (2007).Water quality parameters along rivers. Int. J. Environ. Sci. Tech., 4 (1), 159-167 (9 pages).

Baptista, J. D. C.; Davenport R. J.; Donnelly, T.; Curtis , T. P.; Rayne, D., ( 2008). The microbial diversity of laboratoryscale wetlands appears to be randomly assembled.Water. Res., 42 (12), 3182-3190 (9 pages).

Baptista, J. D. C.; Donelly, T.; Rayne, D.; Davenport, R. J., (2003). Microbial mechanisms of carbon removal in subsurface flow wetlands. Water Sci. Tech., 48(5), 127-134 (8 pages).

Brix, H.; Arias, C. A.; Del Bubba, M., (2001). Media selection for sustainable phosphorus removal in subsurface flow constructed wetlands. Water Sci. Tech., 44 (11-12), 47-54 (8 pages).

Brix, H.; Arias, C. A., (2005). The use of vertical flow constructed wetlands for on-site treatment of domestic wastewater. New Danish guidelines., Ecol. Eng., 25 (5), 491-500 (10 pages).

Calheiros, C. S. C.; Rangel, A. O. S. S.; Castro, P. M. L., (2009). Treatment of industrial wastewater with two-stage constructed wetlands planted with Typha latifolia and Phragmites australis. Bioresour. Tech., 100 (13), 32053213 (9 pages).

Cooper, P. F., (1999). A review of the design and performance of a vertical-flow and hybrid reed bed treatment systems. Water Sci. Tech., 40 (3), 1-9 (9 pages).

Coveney, M. F.; Sites, D. L.; Lowe, E. F; Battoe, L. E.; Conrow, R., (2002). Nutrient removal from eutrophic lake water by wetland filtration. Ecol. Eng., 19 (2), 141-159 (19 pages).

Edwards, K. R.; Cizkova, H.; Zemanova, K.; Santruckova, H., (2006). Plant growth and microbial processes in a constructed wetland planted with Phalaris arundinacea. Ecol. Eng., 27 (2), 153-165 (9 pages).

Enriquez, S.; Duarte, C. M.; Sand-Jensen, K., (1993). Patterns in decomposition rates among photosynthetic organisms: the importance of detritus C: N: P content. Oecologia, 94 (4), 457-471 (15 pages).

Harikumar, P. S.; Nasir, U. P.; Mujeebu Rahman, M. P., (2009). Distribution of heavy metals in the core sediments of a tropical wetland system. Int. J. Environ. Sci. Tech., 6 (2), 225-232 (8 pages).

Igbinosa, E. O.; Okoh, A. I., (2009). Impact of discharge wastewater effluents on the physico-chemical qualities of a receiving watershed in a typical rural community. Int. J. Environ. Sci. Tech. 6 (2), 175-182 (8 pages).

Juang, D. F.; Chen, P. C., (2007). Treatment of polluted river water by a new constructed wetland. Int. J. Environ. Sci. Tech., 4 (4), $481-488$ (8 pages).

Kayser, K.; Kunst, S., (2005). Processes in vertical-flow reed beds - nitrification, oxygen transfer and soil clogging. Water Sci. Tech., 51 (9), 177-184 (8 pages).

Kantawanichkul, S.; Kladprasert, S.; Brix, H., (2009). Treatment of high-strength wastewater in tropical vertical 


\section{B. Cheng et al.}

flow constructed wetlands planted with Typha angustifolia and Cyperus involucratus. Ecol. Eng., 35 (2), 238-247 (10 pages).

Konnerup, D.; Thammarat Koottatep, T.; Brix, H., (2009). Treatment of domestic wastewater in tropical subsurface flow constructed wetlands planted with Canna and Heliconia. Ecol. Eng., 35 (2), 248-257 (10 pages).

Koottatep, T.; Polprasert, C.; Oanh, N. T. K.; Heinss, U.; Montangero, A.; Strauss, M., (2001). Septage dewatering in vertical-flow constructed wetlands located in the tropics. Water Sci. Tech., 44 (2-3), 181-188 (8 pages).

Korkusuz, E. A.; Beklioglu, M.; Demirer, N.G., (2005). Comparison of the treatment performances of blast furnace slag-based and gravel-based vertical flow wetlands operated identically for domestic wastewater treatment in Turkey. Ecol. Eng., 24 (3), 187-200 (14 pages).

Li, L. F.; Li, Y. H.; Biswas, D. K.; Nian, Y. G.; Jiang G., (2008). Potential of constructed wetlands in treating the eutrophic water: Evidence from Taihu Lake of China., Bioresource Tech., 99 (6), 1656-1663 (8 pages).

Lin, Y. F.; Jing, S. R.; Lee, D. Y.; Wang, T. W., (2002). Nutrient removal from aquaculture wastewater using a constructed wetlands system. Aquaculture, 209 (1-4), 169-184 (16 pages).

Lu, X. M.; Huang, M. S., (2010). Nitrogen and phosphorus removal and physiological response in aquatic plants under aeration conditions. Int. J. Environ. Sci. Tech., 7 (4), 665 674 (10 pages)

Luederitz, V.; Eckert, E.; Lange-Weber, M.; Lange, A.; Gersberg, R. M., (2001). Nutrient removal efficiency and resource economics of vertical flow and horizontal flow constructed wetlands. Ecol. Eng., 18 (2), 157-171 (15 pages).

Mahvi, A.H., (2008). Application of agricultural fibers in pollution removal from aqueous solution. Int. J. Environ. Sci. Tech., 5 (2), 275-285(11 pages).

Merlin, G.; Pajean, J. L.; Lissolo, T., (2002). Performances of constructed wetlands for municipal wastewater treatment in rural mountainous area. Hydrobiologia, 469 (1-3), 87-98 (12 pages).

Nameni, M.; Alavi, Moghadam M. R.; Arami, M., (2008). Adsorption of hexavalent chromium from aqueous solutions by wheat bran. Int. J. Environ. Sci. Tech., 5 (2), 161-168 (8 pages).

Nouri, J., Danehkar, A., Sharifipour, R., (2008). Evaluation of ecotourism potential in the northern coastline of the Persian Gulf. Environ. Geo., 55 (3) 681-686 (6 pages).
Nwuche, C. O.; Ugoji, E. O, (2008). Effects of heavy metal pollution on the soil microbial activity. Int. J. Environ. Sci. Tech., 5 (3), 409-414 (6 pages).

Nwuche, C. O.; Ugoji, E. O, (2010). Effect of co-existing plant specie on soil microbial activity under heavy metal stress. Int. J. Environ. Sci. Tech., 7 (4), 697-704 (8 pages).

OECD., (1996). Guideline for testing of chemicals simulation test-aerobic sewage treatment. technical report. Organisation for Economic Co-operation and Development (OECD), Paris, France.

Okafor, E.C.; Opuene, K., (2007). Preliminary, assessment of trace metals and polycyclic aromatic hydrocarbons in the sediments. Int. J. Environ. Sci. Tech., 4 (2), 233-240 (8 pages).

Prochaskaa, C. A.; Zouboulisa, A. I.; Eskridgeb, K. M., (2007) Performance of pilot-scale vertical-flow constructed wetlands, as affected by season, substrate, hydraulic load and frequency of application of simulated urban sewage. Ecol. Eng., 31 (1), 57-66 (10 pages).

Prochaska, C. A.; Zouboulis, A. I., (2009). Treatment performance variation at different depths within vertical subsurface-flow experimental wetlands fed with simulated domestic sewage. Desalination, 237 (1-3), 367-377 (11 pages).

Seo, D. Ch.; Cho, J. S.; Lee, H. J., Heo, J. S., ( 2005). Phosphorus retention capacity of filter media for estimating the longevity of constructed wetland. Water Res. 39 (11), 2445-2457 (13 pages).

Stottmeister, U.; Wiessner, A.; Kuschk, P.; Kappelmeyer, U.; Kappstner, M.; Bederski, O.; Muller, R.A.; Moormann, H., (2003). Effects of plants and microorganisms in constructed wetlands for wastewater treatment. Biotechnol. Adv., 22 (12), 93-117 (25 pages).

Tang, X. Q.; Huang, S. L.; Fciwem, M.S., (2009). Comparison of phosphorus removal between vertical subsurface flow constructed wetlands with different substrates. Water Environ. J. 23 (3), 180-188 (9 pages).

Tsihrintzis, V. A.; Akratos, C. S.; Gikas, G. D.; Karamouzis, D.; Angelakis, A.N., (2007). Performance and cost comparison of a FWS and a VSF constructed wetland systems. Environ. Tech., 28 (6), 621-628 (8 pages).

Zurita, F.; De, A.J.; Belmont, M.A., (2006). Performance of laboratory-scale wetlands planted with tropical ornamental plants to treat domestic wastewater. Water Qual. Res. J. Can., 41 (4), 410-417 (8 pages).

AUTHOR (S) BIOSKETCHES

Cheng, B., Associate professor, Department of Biology and Chemistry, Huainan Normal University, 238 The west Tongshan Road, Huainan 232001, China, Email: bcheng123456@126.com

Hu, C. W., Ph.D., School of Life Science, Linyi Normal University, 18 Tongda Road, Linyi 276005, China. Email: changwei.hu@163.com

Zhao, Y. J., Ph.D., Environmental Science and Engineering Department, Fudan University, 220 Handan Road, Shanghai, 200433, China Email: zyjun2007@126.com

How to cite this article: (Harvard style)

Cheng, B.; Hu, C. W.; Zhao, Y. J., (2011). Effects of the plant development and pollutant loading on performance of vertical subsurface flow constructed wetlands. Int. J. Environ. Sci. Tech., 8 (1), 177-186. 